\title{
Standardizing Climate Education in New York State
}

\section{Ingrid J. Paredes, Steven Farrell, Omar Gowayed}

New York University, Tandon School of Engineering, Chemical and Biomolecular Engineering, Brooklyn, New York http://doi.org/10.38126/JSPG170118

Corresponding author: ijparedes@nyu.edu

Keywords: climate education; climate curriculum; schools; climate change; New York Senate; New York

Executive Summary: In July 2019, the New York State legislature signed the Climate Leadership and Community Protection Act into law. The ambitious act sets targets to establish climate resiliency statewide through initiatives including reducing gas emissions, improving infrastructure, and providing job training. In response, several state senators have called for education reform to accordingly prepare the next generation for the climate crisis. We evaluate three climate education bills (S7341, S6837, and S6877) currently in committee in New York State. S7341, sponsored by Senator Andrew Gounardes and known as the Model Curriculum bill, proposes an environmental education curriculum for K-12 students. S6877, sponsored by Senator Rachel May and called the Regents Climate Amendment, makes recommendations to the Board of Regents on climate science in high school science classes. S6837, a Climate Education Grants Program sponsored by Senator Todd Kaminsky, provides support for teacher training and local climate resiliency projects. We examined these bills with respect to their effectiveness, administrative burden, and efficiency in the delivery of a climate education. We found the Model Curriculum bill to be the most effective way to educate and prepare students for the climate crisis. However, New York State must support educators with proper training and funding to provide quality climate education. We therefore recommend that the New York Senate pass the Model Curriculum bill and the Climate Education Grants Program.

\section{Background}

Scientific consensus states that anthropomorphic climate change is occurring. Unfortunately, up to half of the United States population does not believe the consensus, and nearly one fifth of the country's population denies climate science altogether (Cook et al. 2016; Meehan, Levy, and Collet-Gildard 2018). Still, the United States is the second largest polluter worldwide. To meet the Intergovernmental Panel on Climate Change (IPCC)'s call for a global decrease in net $\mathrm{CO}_{2}$ emissions by $45 \%$ by 2030 would require overhauling our energy, infrastructure, and economic systems (Masson-Delmotte 2019; Union of Concerned Scientists 2008). In the United States, the IPCC's findings have fueled political pressure behind aggressive policies like the Green New Deal (Galvin and Healy 2020; H.R. 109 2019). In support of this effort, in July 2019 the New York state legislature passed S6599, or the Climate Leadership and
Community Protection Act (CLCPA) (S. 6599 N.Y. 2019). The CLCPA sets a target to reduce statewide gas emissions by $85 \%$ by 2050 and outlines the need to establish climate resiliency in New York State through job training, infrastructure investments, and scientific research.

\section{i. Current gaps within climate education}

Given the poor understanding of climate science nationwide, educators have argued that our educational curricula must also adequately equip students with the knowledge needed to understand the challenges of the climate crisis (Meehan, Levy, and Collet-Gildard 2018; National Science Teaching Association 2010). To date, no nationwide standard curriculum on the climate crisis currently exists. Furthermore, few educators have felt prepared to teach climate change in the classroom, while other teachers have reported discomfort at teaching the 
subject (Hannah and Rhubart 2019). Most teachers who teach climate science have also used ineffective teaching methods, including the "both sides" approach that encourages students to debate the validity of scientific consensus (Plutzer et al. 2016). This approach has promoted misconceptions of scientific consensus rather than productive discussion of solutions and impacts (Hannah and Rhubart 2019).

\section{ii. Current actions to address these gaps}

The Next Generation Science Standards, a set of expectations for K-12 student knowledge and ability developed by states under the direction of the National Research Council (NRC) and Achieve, and supported by the Carnegie Corporation of New York, have sought to address this by including anthropomorphic climate change in its curriculum. Nineteen states, including New York, have adopted the standards, but discussion of climate is limited to earth science courses, which are not required for many students (Hannah and Rhubart 2019). California and Washington, which have adopted the standards, have passed additional legislation to improve climate literacy within their curricula (S.B. 720 Calif. 2018; S.B. 6032 Wash. 2017). In Washington, a grant program called "ClimeTime," has been passed, to provide educators with funds to provide climate education (ClimeTime 2020). The program has been popular among educators as it has provided contextual and active learning experiences for their students, reinforcing science concepts in the context of local impacts of the climate crisis. One example of a success story reported that students from Cascade High School were able to learn about the large-scale disappearance of the American Pikas through a field trip to their natural habitat instead of a less interactive lecture (ClimeTime 2019). Other states, including New York, currently lack comparable programs.

\section{Options for selecting climate curriculum}

To address the gap in climate education needed to prepare students to meet the CLCPA goals, legislators in the New York Senate have proposed three bills to improve climate education in New York State:

- A model curriculum for environmental education in K-12 public schools, sponsored by Senator Andrew Gounardes (S. 7341 N.Y. 2019)
- A requirement for the Commissioner of Education to recommend the Board of Regents to adopt climate science instruction in senior high schools, sponsored by Senator Rachel May (S. 6877 N.Y. 2019)

- A climate education grants program for educators and community organizations, sponsored by Senator Todd Kaminsky (S. 6837 N.Y. 2019)

The Model Curriculum bill and Regents recommendation seek to standardize climate education statewide; the Climate Education Grants Program would provide funding for educators should either bill pass. Like the ClimeTime program, the Climate Education Grants Program would provide teachers with professional support to address the disparities in preparedness for climate education among educators. The bill would also support teachers to provide contextual learning experiences for students, which have proven successful through ClimeTime. We therefore first recommend the NY State Senate pass the Climate Education Grants Program, as adequate funding and support is necessary for the success of either the model curriculum or the Regents recommendation.

\section{Methods for selection of a New York climate curriculum}

We now compare the impact of the model curriculum, the Regents recommendation, and inaction on climate education in New York State. We use the following criteria to compare the policy options presented:

- Program Effectiveness: What is the scope of the proposed bill? Who will be impacted, and what will that impact be on the quality of the STEM education students in NY are currently receiving?

- Administrative Burden: What impact will the options have on educational resources, such as staff capacity, both at the state level New York State Education Department (NYSED) and local level (primary and secondary schools)?

- Efficiency: What are the benefits of each option compared with their associated costs (including time, resources, and spending)? 
i. Option 1: Pass the Regents recommendation to require the commissioner of education to recommend a climate curriculum for high school students

\section{Opportunities}

The Regents recommendation outlines provisions that require the Commissioner of Education to make secondary school climate education recommendations to the New York State Board of Regents. Senator May justifies climate education as necessary to prepare the next generations of adults to tackle emissions targets outlined in the CLCPA. The bill effectively outlines educational targets for students, including lessons about greenhouse gases, the driving factors of climate change, and human contribution to emissions. The bill also requires the Commissioner to consider fiscal impact on NYSED and local school districts, as well as time lost from other courses to accommodate climate modules within the limited time of a school year. The bill sets clear and timely deadlines for the Board of Regents to vote on the Commissioner's proposals.

\section{Obstacles}

Despite its detail, we identify several issues with the Regents recommendation. First, there is little binding power in the legislation. This top-down approach to standardizing educational requirements depends on the Board of Regents' decision to accept the Commissioner's proposals. No data was available regarding how often the board accepts or rejects recommendations, leaving the bill's effectiveness subject to speculation.

The bill also does not require any further action other than a written report should the Board of Regents reject the proposals. Second, the proposed changes in curricula are limited in reach. New York State adheres to the Next Generation Science Standards, which does not require climate science to be taught in any classes but earth science, an elective course (Hannah and Rhubart 2019). Students who do not take an earth science course will therefore have limited exposure to climate science education.

Furthermore, despite efforts to increase inclusivity in STEM, unequal education opportunities are already present throughout the U.S. and in New York State (Weiss et al. 2015). For example, the New York City school system, which provides less access to STEM to low income students of color (The New York Equity
Coalition 2019; New York City Environmental Justice Alliance 2018). This bill would fail to ensure climate education for all students and exacerbate these inequalities. The bill also does not specify the frequency with which this curriculum will be reviewed. For the resources required to enable toplevel changes to the state curriculum (including personnel and working hours), we find it insufficient to expand the scope of climate education.

\section{ii. Option 2: Adopt the model curriculum to standardize environmental education in $\mathrm{K}$-12 schools}

\section{Opportunities}

In a bottom-up approach, the Model Curriculum bill establishes an environmental education curriculum for K-12 students that introduces climate change into all courses, rather than just science courses. The bill aligns itself with the CLPCA goals of civic preparedness for the climate crisis. However, this bill offers a more thorough list of topics to cover under climate change, such as resource conservation and environmental justice. The broad scope of the curriculum aligns with the National Science Teaching Association's call for science education to "provide an authentic learning context by examining the societal dimensions of a scientific issue, such as political, economic, and ethical considerations" (National Science Teaching Association 2010). This creates a well-rounded and interconnected curriculum that allows for one to consider STEM, history, economics, and politics within intersectional issues as opposed to separate elective courses.

Previous studies have also shown that contextual learning, in which students can relate to the subject matter based on their own experiences, enhances understanding of climate science. For example, students using tools to measure their local air temperature and quality developed not only a better understanding about the difference between weather and climate but a better understanding of the scientific method (Hallar, McCubbin, and Wright 2011; McNeill and Vaughn 2010; Monroe, et al. 2017). The bill would also be implemented within one academic year following the bill's passing, ensuring its implementation in New York schools.

\section{Obstacles}

Compared to the Regents recommendation, the model curriculum creates a greater burden on school 
resources and impacts the curricula content in all subjects, not just the sciences. The state recently had major changes to curricula under the New York Next Generation Learning Standards in 2017 (New York State Department of Education). This new bill would again require all teachers to invest time in revising lesson plans to accommodate this model curriculum, not just science teachers. The requirement for the Commissioner to revisit this program every four years and potentially require committee review to update the curriculum adds further administrative personnel hours to implementation. While the bill states that the school districts shall provide the needed support to implement the curriculum, it does not outline the source of such funds, or what form that support would take for educators.

iii. Option 3: Adopt neither amendment to the education law of New York State

To progress none of the bills presented would place New York State in line with several other states that have had climate education bills fail in the state senate. This creates virtually no impact on the subjects currently being taught per Regents curriculum and does not require any loss of the current educational content. However, this fails to improve STEM education in New York State and to prepare students for the challenges of the climate crisis. The prospects for climate resiliency would not be met and the overall effectiveness would be poor in reaching the targets outlined in the CLCPA.

\section{Recommendations}

We recommend that the New York State Senate pass the Model Curriculum bill sponsored by Senator Gournades. We also find that it is necessary to fund and provide teacher training to fully establish a robust climate curriculum for students in primary and secondary education. We therefore also recommend passing the Climate Education Grants Program sponsored by Senator Kaminsky, which establishes a grant and training program for developing sustainability and climate research projects in schools.

Teachers without a background in the climate issues associated with their field would have ample training and funding opportunities to teach climate curriculum. This bill combination would most effectively prepare students for the present and future environmental challenges we face. The benefits would not be limited to education in the context of physical sciences but also promote growth in social aspects such as leadership and environmental equity. These policies make the best use of available resources to not only improve STEM education in New York but to also establish the state as a model leader in climate action and further bolster the recently passed Climate Leadership and Community Protection Act.

\section{References}

ClimeTime. 2019. "Stressed Out Pikas Help Cascade High School Students Learn about Climate Science." Accessed August 11, 2020. https://www.climetime.org/stressed-out-pikashelp-cascade-high-school-students-learn-aboutclimate-science/

ClimeTime. 2020. "Climate Science Learning." Accessed March 21, 2020. https://www.climetime.org/

Cook, John, Naomi Oreskes, Peter T. Doran, William R. L. Anderegg, Bart Verheggen, Ed W. Maibach, J. Stuart Carlton, et al. 2016. "Consensus on Consensus: A Synthesis of Consensus Estimates on Human-Caused Global Warming."

Environmental Research Letters 11, no. 4. https://doi.org/10.1088/17489326/11/4/048002
Galvin, Ray, and Noel Healy. 2020. "The Green New Deal in the United States: What It Is and How to Pay for It." Energy Research \& Social Science 67. https://doi.org/10.1016/j.erss.2020.101529

H.R. 109, 116th Cong. (2019). https://www.congress.gov/bill/116thcongress/house-resolution/109

Hallar, A. Gannet, Ian B. McCubbin, and Jennifer M. Wright. 2011. "Change: A Place-Based Curriculum for Understanding Climate Change at Storm Peak Laboratory, Colorado." Bulletin of the American Meteorological Society 92, no. 7: 909-18. https://doi.org/10.1175/2011BAMS3026.1

Hannah, A. Lee, and Danielle Christine Rhubart. 2019. "Teacher Perceptions of State Standards and Climate Change Pedagogy: Opportunities and Barriers for Implementing Consensus-Informed Instruction on Climate Change." Climatic Change 158, no. 3-4: 377-92. https://doi.org/10.1007/s10584-019-02590-8 
Weis, Lois, Margaret Eisenhart, Kristin Cipollone, Amy E. Stich, Andrea B. Nikischer Andrea B. Nikischer, Jarrod Hanson, Sarah Ohle Leibrandt, Carrie D. Allen, Rachel Dominguez. 2015. " In the Guise of STEM Education Reform: Opportunity Structures and Outcomes in Inclusive STEM-Focused High Schools" American Education Research Journal 52, no. 6: 1024-105.

https://doi.org/10.3102/0002831215604045

Masson-Delmotte, V., Panmao Zhai, Hans-Otto Pörtner, Debra Roberts, Jim Skea, Priyadarshi R. Shukla, Anna Pirani, Wilfran Moufouma-Okia, Clotilde Péan, Roz Pidcock, Sarah Connors, J. B. Robin Matthews, Yang Chen, Xiao Zhou, Melissa I. Gomis, Elisabeth Lonnoy, Tom Maycock, Melinda Tignor, and Tim Waterfield (eds.). 2019. "Global Warming of $1.5^{\circ} \mathrm{C}$. IPCC Special Report 2018". Intergovernmental Panel on Climate Change. https://www.ipcc.ch/sr15/

McNeill, Katherine L., and Meredith Houle Vaughn. 2010. "Urban High School Students' Critical Science Agency: Conceptual Understandings and Environmental Actions around Climate Change." Research in Science Education 42, no. 2: 373-99. https://eric.ed.gov/?id=EJ958369

Meehan, Casey R., Brett L. M. Levy, and Lauren ColletGildard. 2018. "Global Climate Change in U.S. High School Curricula: Portrayals of the Causes, Consequences, and Potential Responses." Science Education 102, no. 3: 498-528. https://doi.org/10.1002/sce.21338.

Monroe, Martha C., Richard R. Plate, Annie Oxarart, Alison Bowers, and Willandia A. Chaves. 2017. "Identifying Effective Climate Change Education Strategies: A Systematic Review of the Research." Environmental Education Research 25, no. 6: 791812. https://doi.org/10.1080/13504622.2017.13608 $\underline{42}$

National Science Teaching Association. 2010. "NSTA Position Statement: Teaching Science and Technology in the Context of Societal and Personal Issues." Last modified July 2016. Accessed March 21, 2020.

https://www.nsta.org/about/positions/societalpersonali ssues.aspx.
New York City Environmental Justice Alliance. 2018. "Midway to 2030: Building Resiliency and Equity for a Just Transition." NYC Climate Justice Agenda 2018. https://www.nyc-eja.org/nyc-climatejustice-agenda/

"Next Generation Learning Standards". New York State Department of Education. Accessed July 24, 2020. http://www.nysed.gov/next-generationlearning-standards.

Plutzer, Eric, A. Lee Hannah, Joshua Rosenau, Mark S. McCaffrey, Minda Berbeco, and Ann H. Reid. 2016. "Mixed Messages: How Climate is Taught in America's Schools." Oakland, CA: National Center for Science Education. http://ncse.com/files/MixedMessages.pdf

S. 6599, 2019-2020 Reg. Sess. (New York 2019). https://www.nysenate.gov/legislation/bills/201 9/s6599

S. 6837, 2019-2020 Reg. Sess. (New York 2019). https://www.nysenate.gov/legislation/bills/201 9/s6837

S. 6877, 2019-2020 Reg. Sess. (New York 2019). https://www.nysenate.gov/legislation/bills/201 9/s6877

S. 7341, 2019-2020 Reg. Sess. (New York 2020). https://www.nysenate.gov/legislation/bills/201 $9 / \mathrm{s} 7341$

S.B. 6032, 65th Legislature, 2018 Reg. Sess. (Wash. 2017). S.B. 6032, 65th Legislature, 2018 Reg. Sess. (Wash. 2017). S.B. 720, 2017-2018 Reg. Sess. (Calif. 2018). https://leginfo.legislature.ca.gov/faces/billTextCl ient.xhtml?bill id=201720180SB720

The New York Equity Coalition. 2019." The Gatekeepers: How school district policies can open or close the door for students to take advanced coursework". The Education Trust-New York. https://equityinedny.edtrust.org/wpcontent/uploads/sites/14/2019/11/Gatekeeper $\underline{\text { s.pdf }}$

Union of Concerned Scientists. 2008. "Each Country's Share of CO2 Emissions." Last modified May 11, 2020. Accessed July 24, 2020. https://www.ucsusa.org/resources/eachcountrys-share-co2-emissions

Ingrid J. Paredes is a Ph.D. candidate in chemical engineering at NYU Tandon School of Engineering in Brooklyn, NY as a member of the Hybrid Nanomaterials Laboratory. The focus of her thesis research is the development of novel nanomaterial systems for clean energy technologies. She currently serves as co-chair of March for Science NYC.

Steven Farrell received his B.S and M.S. in Chemical Engineering from Drexel University, and is pursuing a Ph.D. in Materials Chemistry at New York University Tandon School of Engineering as a member of the Hybrid Nanomaterials Laboratory. He studies two-dimensional nanostructures and materials for sustainable catalysis 
applications and previously was a coordinator of NYU's Science Policy and Diplomacy course. Additionally, he has coordinated the \#StreamForScience digital event collaboration with March for Science NYC.

Omar Gowayed is a Ph.D. Candidate in Materials Chemistry at New York University Tandon School of Engineering, and currently serves as a co-chair of March for Science NYC. He specializes in Non-Photochemical Laser Induced Nucleation, a technique of shooting high powered lasers to induce phase changes in certain liquid materials. Although his research is with lasers, he teaches a vertical farming class called Urban Food Lab in which students run sustainability and farm focused mini-projects to learn about research and design while working on an aquaponic farm. He was also a coordinator of NYU's Science Policy and Diplomacy course. 